\title{
Cultural Values, CEO Risk Aversion and Corporate Takeovers ${ }^{\dagger}$
}

\author{
BART FRIJNS ${ }^{\mathrm{a},{ }^{*},}$, AARON GILBERT ${ }^{\mathrm{a}}$, THORSTEN LEHNERT ${ }^{\mathrm{b}}$ \\ and ALIREZA TOURANI-RAD ${ }^{\mathrm{a}}$
}

${ }^{\mathrm{a}}$ Department of Finance, Auckland University of Technology, Auckland, New Zealand ${ }^{b}$ Luxembourg School of Finance, Luxembourg.

We like to thank seminar participants at the Georg August University, Goettingen, Germany, Massey University, Auckland, New Zealand, and the University of Technology Sydney, Australia, for their useful comments and suggestions.

*Corresponding author. Tel.: +64 99219999 (ext. 5706); Fax: +64 9921 9940; Email: bfrijns@aut.ac.nz 


\title{
Cultural Values, CEO Risk Aversion and Corporate Takeovers
}

\begin{abstract}
$\underline{\text { Abstract }}$
We explicitly examine the role of culture in corporate takeover decisions. Prior research suggests that the risk aversion of CEOs affects their takeover decisions. In this paper, we argue that managerial risk aversion at a national level is a cultural trait and affects the net synergies. CEOs of firms located in countries with higher level of risk aversion, measured by Hofstede's (2001) uncertainty avoidance score, show less takeover activity, engage more in diversifying takeovers and require higher premiums on takeovers. Required net synergies are higher for smaller firms, relatively larger deals, and for firms that engage in more takeover activity.
\end{abstract}

JEL Codes: D81; G34; M14.

Key Words: Financial Decision Making; Risk Aversion; Synergies; Culture; Takeovers. 


\section{Introduction}

The role of culture and cultural values in finance and financial decision making has recently been explored by several studies. These studies suggest that culture can explain the structure and development of financial institutions and provide insight into the basis of financial decision making by individuals beyond traditional finance arguments. For example, at the institutional level, Stulz and Williamson (2003) link differences in culture (proxied by language and the principle religion of a country) to the level of investor protection and creditor rights within a country. Licht, Goldschmidt and Schwartz (2005) and Doidge, Karolyi and Stulz (2007) argue that corporate governance is a function of a country's culture. In fact, Doidge et al. show that culture is more important than firm-specific aspects in explaining differences in corporate governance. Research has further established that culture has an impact on decisions made at the individual level. Halek and Eisenhauer (2001) and Hillary and Hui (2009), for instance, show a link between religion, a common proxy for culture, and individual risk aversion. Graham, Harvey and Puni (2009), using survey data in the U.S, demonstrate that CEOs are not immune to the effects of culture. They find that CEOs' decision making is influenced by cultural values, such as risk aversion. This idea that culture influences managerial decision making contradicts the traditional view of managers as disassociated agents undertaking shareholder value maximizing decisions and could explain why companies undertake seemingly irrational decisions.

One question in corporate finance that has yet to be resolved convincingly is why firms undertake acquisitions. A wide range of literature has demonstrated that many corporate acquisitions are hard to justify from a shareholder value maximization perspective. Several studies have suggested that CEO's personal interests often drive these decisions, one factor 
being the CEO's degree of risk aversion. Since CEOs have a disproportionate exposure to the performance of the firm and are unable to fully diversify, takeovers have a direct effect on their personal wealth. Amihud and Lev (1981) explored this idea and found evidence that risk aversion indeed causes managers to acquire outside their core industries as a way to diversify their personal wealth. This suggests that the degree of CEO risk aversion has an impact on takeovers as has been suggested by various other studies (e.g. May, 1995; Hall and Murphy, 2002; and Lewellen, 2006).

The research in this area to date has been limited by the difficulty in measuring risk aversion. Previous studies have either relied on CEO characteristics such as age or tenure, or have undertaken surveys resulting in small response rates. Further, surveys limit studies to examining one or a small number of markets. In this paper, we explore the question of how risk aversion as a cultural trait impacts acquisition decisions at a country level using a national measure of risk aversion, Hofstede's (2001) uncertainty avoidance measure. We argue that since takeovers are a risk to the firm's value and hence a CEO's position, a more risk averse $\mathrm{CEO}$ will require higher compensation before undertaking an acquisition. Hence, a more risk-averse CEO will only engage in a takeover if the expected net synergies ${ }^{1}$ are large enough.

We first develop a theoretical framework based on Aktas et al. (2009) that establishes a link between CEO risk aversion and net synergies. We then empirically examine this link using Hofstede's (2001) degree of uncertainty avoidance as a measure for risk aversion and cumulative abnormal returns (CARs), as a measure of net synergy. Using a sample of 25,843

\footnotetext{
${ }^{1}$ Net synergies refer to the value of the target to the acquiring firm minus the price paid for the target firm.
} 
takeovers from 39 countries, we confirm that CEOs from more risk avoiding nations engage in less takeover activity and when they engage in a takeover, they have a preference for diversifying takeovers (see Amihud and Lev, 1981). We further find that risk aversion has a strong positive relationship with CARs, indicating that CEOs from more risk averse nations require higher premiums on takeovers. We also find that relative deal size is positively related to CARs, indicating that larger takeovers require higher premiums. However, the impact of deal size is partly explained by risk aversion, i.e. for small deals risk aversion has no impact on CARs, for large deals it has. We perform several robustness checks to validate our results.

The paper proceeds as follows. In section 2, we provide a framework to show the relationship between CEO risk aversion and net synergies and develop testable hypotheses. Section 3 discusses the data employed in the empirical part of the study and section 4 shows our results. We conclude in section 5 .

\section{CEO Risk Aversion and Net Synergies}

\subsection{Theoretical Framework}

In this section, we argue that the CEO's degree of risk aversion is positively related to the expected net synergies on takeovers. We establish this link by developing a framework that is based on Aktas et al. (2009).

We assume that the CEO is facing a takeover decision on target firm $T$. Let $V_{T}$ be the current market value of the target firm and $\widetilde{s}$ be the potential (percentage) synergies that the acquiring firm can obtain by acquiring the target. The potential synergies, $\widetilde{s}$, are not known 
with certainty, but come from a distribution with a mean and variance known to the CEO of the acquiring firm, (for example, we can assume that $\widetilde{s}$ is a normally distributed variable with mean $\mu_{s}$ and variance $\sigma_{s}^{2}$ ). Let $\widetilde{V}_{T}$ be the value of the target firm to the acquirer, i.e.,

$$
\widetilde{V}_{T}=V_{T}(1+\widetilde{s})
$$

which is also a random variable dependent on $\widetilde{s}$. The net synergies will be defined as the difference between the value of the target to the acquirer and the price paid for the target firm, $P$, i.e.,

$$
\widetilde{\delta}=\widetilde{V}_{T}-P
$$

which again is a random variable (e.g. given normally distributed synergies, $\widetilde{\delta} \sim N\left(\mu_{\delta}, \sigma_{\delta}\right)$, with $\mu_{\delta}=V_{T}\left(1+\mu_{s}\right)-P$, and $\left.\sigma_{\delta}^{2}=V_{T}^{2} \sigma_{s}^{2}\right)$.

The CEO will need to decide what price, $P$, he is willing to pay for the target. In doing so, we assume that he faces the following decision problem. The CEO has a current wage package, $W$, from which he derives utility $U(W) .^{2}$ Based on the net synergies obtainable, the CEO makes a bid for the target. The bid can be accepted with probability $\phi_{D}$, or can be rejected with probability $\left(1-\phi_{D}\right)$, where $\phi_{D}$ is an increasing function in $P$ (i.e. if the CEO bids more there is a greater probability of the bid being accepted). If the bid gets rejected nothing will happen and the CEO keeps his current utility, $U(W)$. If the deal gets accepted, the acquisition

\footnotetext{
${ }^{2} W$ can be thought of as the present value of his wage package and bonuses conditional on no offer being made for the target firm.
} 
may be successful (i.e. positive net synergies are realized) with probability $\phi_{S}$, where $\phi_{S}$ is a decreasing function in $P$ (i.e. if the CEO offers more, there is a lower probability of positive net synergies being realized). If positive synergies are realized the CEO receives a bonus $C(\widetilde{\delta})$, which is increasing in $\widetilde{\delta}$. As in Aktas et al. (2009), we assume that $C(\widetilde{\delta})$ is linear in $\widetilde{\delta}$, i.e.

$$
C(\widetilde{\delta})=a+b \widetilde{\delta}
$$

consisting of a fixed component $a$ and a variable component $b$ depending on the size of the net synergies. In the case of a successful deal the CEO's total expected utility will be $E[U(W$ $+C(\widetilde{\delta}))]$. However, the acquisition could also be considered a failure with probability $(1-$ $\left.\phi_{S}\right)$. In that case the CEO stands to make a loss $L$ and his total utility will be $U(W-L) .{ }^{3}$ The decision problem facing the CEO is summarized in Figure 1.

\section{INSERT FIGURE 1 HERE}

From this decision problem, we can compute the expected utility of the CEO

$$
E[U]=\left(1-\phi_{D}\right) U(W)+\phi_{D}\left\{\left(1-\phi_{S}\right) U(W-L)+\phi_{S} E[U(W+C(\tilde{\delta})]\},\right.
$$

\footnotetext{
${ }^{3}$ Similar to Aktas et al. (2009), we assume that $L$ represents a major loss to the CEO (e.g. the CEO may lose his job, bonuses or other perks, reputation, etc.). This idea is supported by the findings of, for example, Lehn and Zhao (2006) who show that CEOs who initiate value destroying takeovers incur a much higher probability of being involuntarily replaced.
} 
where we can obtain expressions for $E[U(W+C(\widetilde{\delta}))]$ and $U(W-L)$ by using a first and second order Taylor approximations around $W$. As per Pratt (1964), we obtain

$$
E\left[U(W+C(\widetilde{\delta})]=U(W)+E[C(\widetilde{\delta})] U^{\prime}(W)\right.
$$

and

$$
U(W-L)=U(W)-L U^{\prime}(W)+1 / 2 L^{2} U^{\prime \prime}(W)
$$

where $U^{\prime}(W)$ and $U^{\prime \prime}(W)$ are the first and second order derivatives with respect to $W$. Substituting (5) and (6) into (4) yields

$$
E[U]=U(W)+\phi_{D}\left\{\left(1-\phi_{S}\right)\left(-L U^{\prime}(W)+1 / 2 L^{2} U^{\prime \prime}(W)\right)+\phi_{S} E[C(\widetilde{\delta})] U^{\prime}(W)\right\}
$$

To determine the price at which the CEO will undertake the acquisition, or stated differently, to determine the premium the CEO requires on the takeover, we maximize equation (7) with respect to $P$. Thus we solve

$$
\begin{aligned}
& \frac{\partial E(U)}{\partial P}=\left(\phi_{D} \phi_{S}\right)^{\prime} E[C(\widetilde{\delta})] U^{\prime}(W)-\phi_{D} \phi_{S} b U^{\prime}(W)-\phi_{D}{ }^{\prime}\left(1-\phi_{S}\right) L U^{\prime}(W)+\phi_{D} \phi_{S}{ }^{\prime} L U^{\prime}(W) \\
& +1 / 2 \phi_{D}{ }^{\prime}\left(1-\phi_{S}\right) L^{2} U^{\prime \prime}(W)-1 / 2 \phi_{D} \phi_{S}^{\prime} L^{2} U^{\prime \prime}(W)=0
\end{aligned}
$$

for $E[C(\widetilde{\delta})]$, which yields 


$$
E[C(\widetilde{\delta})]=\frac{\phi_{D} \phi_{S} b+\phi_{D}{ }^{\prime}\left(1-\phi_{S}\right) L-\phi_{D} \phi_{S}{ }^{\prime} L+1 / 2 \phi_{D}{ }^{\prime}\left(1-\phi_{S}\right) L^{2} \gamma-1 / 2 \phi_{D} \phi_{S}{ }^{2} L^{2} \gamma}{\left(\phi_{D} \phi_{S}\right)^{\prime}}
$$

where, assuming that utility is increasing and concave in $W, \gamma=-\frac{U^{\prime \prime}(W)}{U^{\prime}(W)}$ is the Arrow and Pratt coefficient of absolute risk aversion, and $\phi_{D}{ }^{\prime}, \phi_{S}{ }^{\prime}$ and $\left(\phi_{D} \phi_{S}\right)^{\prime}$ are the first-order derivatives with respect to $P$. Note that $\phi_{D}{ }^{\prime}>0$ as the probability of getting a deal accepted increases in $P$, and $\phi_{S}{ }^{\prime}<0$ as the probability of positive net synergies decreases in $P$. Equation (9) shows that there is a positive relationship between the compensation expected by the CEO and his degree of risk aversion (for $\gamma>0, \frac{1}{2} \phi_{D}^{\prime}\left(1-\phi_{S}\right) L^{2} \gamma>0$, as $\phi_{D}^{\prime}>0$, and $-\frac{1}{2} \phi_{D} \phi_{S}^{\prime} L^{2} \gamma>0$, as $\left.\phi_{S}^{\prime}<0\right)$

We can further solve Equation (9) for $\mathrm{E}[\widetilde{\delta}]$ as we have assumed an explicit functional form for $C(\widetilde{\delta})$ :

$$
E[\tilde{\delta}]=\frac{\phi_{D} \phi_{S}}{\left(\phi_{D} \phi_{S}\right)^{\prime}}+\frac{\phi_{D}{ }^{\prime}\left(1-\phi_{S}\right) L-\phi_{D} \phi_{S}{ }^{\prime} L+1 / 2 \phi_{D}{ }^{\prime}\left(1-\phi_{S}\right) L^{2} \gamma-1 / 2 \phi_{D} \phi_{S}{ }^{\prime} L^{2} \gamma}{b\left(\phi_{D} \phi_{S}\right)^{\prime}}-\frac{a}{b}
$$

Several implications can be derived from Equation (10). First, equation (10) shows that the required (expected) net synergies are a positive function of the CEO's risk aversion (since $\phi_{S}{ }^{\prime}$ is negative), i.e. for a given loss $L$ and a given compensation scheme, a higher degree of risk aversion would induce a CEO to offer less, so that greater net synergies can be expected. Second, as a risk-averse CEO would offer less, it is expected that less deals would get 
accepted (as $\phi_{D}$ is increasing in $P$ ). Third, equation (10) demonstrates that the required net synergies are positively related to $L$, i.e. for a given compensation scheme and given risk aversion, expected net synergies need to be greater when the loss is greater. Finally, equation (10) shows that the expected net synergies are negatively related to the fixed proportion of the bonus, i.e. if the CEO receives a large fixed bonus, the required net synergy can be lower, and inversely related to the proportion of the net synergies received by the CEO, i.e., if $b$ is higher, then the required net synergies can be lower, ceteris paribus.

\subsection{Empirical Implementation}

The framework presented above establishes a positive relationship between net synergies and CEO risk aversion. However, net synergies and CEO risk aversion are not directly observable. Therefore, in this section, we first establish a link between net synergies and cumulative abnormal returns (CARs), and second argue that risk aversion at the national level is a cultural trait. As a result, the link between net synergies and CEO risk aversion can be operationalized and tested by examining the relationship between cumulative abnormal returns and cultural traits.

While net synergies are unobservable, they can be evaluated on the basis of CARs. As net synergies $(\widetilde{\delta})$ obtained from the takeover are the gains to the shareholders of the acquiring firm, we can expect the value of the acquiring firm to increase by the value of net synergies created (see also Lehn and Zhao, 2006). The percentage net synergies ( $\widetilde{\delta} / V_{A}$, where $V_{A}$ is the value of the acquirer before the takeover announcement), should be the same as the percentage increase in the share price of the acquirer. Hence, the cumulative abnormal returns (CARs) around the announcement should provide a clear signal of the expected net synergies (assuming markets are efficient in the semi-strong form). 
Further, we argue that risk aversion at the national level is a cultural trait. Geletkanycz (1997) argues that cultural values, and executives' experiences and values affect their decision making. Although experiences may differ depending on the CEO's background, values are defined by a set of shared assumptions often referred to as national culture. Geletkanycz notes: "As members of national societies, managers not only contribute to the collective formulation of cultural norms and views, they experience social reinforcement pressures which bring their individual-level assumptions and preferences into close alignment with those of their native culture" (Geletkanycz, 1997, pp. 617).

The importance of culture in decision making can be observed in studies on the economic analysis of religion. Prior research has shown a positive relationship between risk aversion and religiosity. Weber (1905) established a link between the development of capitalism and Protestantism, and was perhaps the first to relate religion to risk aversion. In his words: "One recent writer has attempted to formulate the difference of their [Protestants and Catholics] attitudes toward economic life in the following manner: The Catholic is quieter, having less of the acquisitive impulse; he prefers a life of the greatest possible security, even with a smaller income, to a life of risk and excitement, even though it may bring the chance of gaining honor and riches. The proverb says jokingly, 'either eat well or sleep well'. In the present case the Protestant prefers to eat well, the Catholic to sleep undisturbed." More recently, Halek and Eisenhauer (2001) find a relationship between religion and risk aversion in a survey conducted on insurance purchases. They suggest that much of one's personal identity is derived from social group membership as one's nationality, ethnicity, religion and occupation. This tendency to conform to the dominant values and behavior of the group has implications for firm behaviour and, therefore, risk taking. Hillary and Hui (2009) confirm 
the relation between religiosity and individual risk aversion, finding that firms located in US counties with high levels of religiosity have lower investment rates in both tangible and intangible assets.

Following Hillary and Hui (2009), we argue that individuals with the same cultural norms and views are clustered in a country, and that firms in this country and the people within these firms are driven by the same cultural norms and values. As a consequence, risk aversion at a national level should be reflected in a firm's corporate culture and its behaviour, particularly that of its management (see Geletkanycz, 1997). This should generate more risk averse behavior, on aggregate, for firms located in more uncertainty avoiding/risk averse countries and, therefore, should generate differences in risk aversion across countries.

The above mentioned literature suggests that cultural values affect the aggregate behavior of individuals within a country, even though individuals may exhibit different behaviors. In addition, there has been a vast amount of empirical literature on the impact of culture on economic decision making (see e.g. Kirkman et al., 2006 for an overview of this literature). Many of these studies rely on the cultural framework provided by Hofstede (2001). Hofstede (2001) defines four cultural dimensions that capture the cultural traits of members of that society. These dimensions are: Uncertainty Avoidance; Individualism; Power Distance and Masculinity-Femininity. Of these four dimensions, we are particularly interested in uncertainty avoidance. According to Hofstede (2001), uncertainty avoidance refers to the extent to which members of a society feel uncomfortable with unstructured, uncertain situations. 
Although Hofstede's (2001) uncertainty avoidance measure captures more than just risk aversion, a number of studies have used uncertainty avoidance as a proxy for risk aversion. For example, Kwok and Tadesse (2006) show that high uncertainty avoiding countries are characterized by a (relatively risk-averse) bank-based financial system, and low uncertainty avoiding countries by a market-based financial system. Chui and Kwok (2008) further show that high uncertainty avoiding countries have higher levels of life insurance consumption. Finally, Beugelsdijk and Frijns (2010), in a cross-country study on international mutual funds' asset allocations, show that high uncertainty avoiding countries allocate fewer funds to foreign markets and display a greater home bias. These studies demonstrate a link between uncertainty avoidance and risk aversion.

Based on the two arguments presented above, we expect that CARs around the takeover announcement reflect the net synergies created by a takeover, while Hofstede's (2001) uncertainty avoidance has an established relationship with risk aversion. We use these proxies to test various implications of the framework presented in section 2.1.

\section{Data}

We obtain data on mergers and acquisitions undertaken around the world from the Thomson One Banker database. This database contains detailed information on mergers and acquisitions around the world, including details on the specific deal (date of announcement, completion status, date of completion, percentage of shares bought, dollar size of the deal, etc.), the acquirer (acquirer nationality, industry, etc.) and the target (target nationality, industry, etc.). From this database we collect data on all mergers and acquisitions over the period January 1990 to August 2008. The database contains data on 136,086 mergers and 
acquisitions attempted within this period. However, to be included in the sample, we only select those acquisitions for which the deal size is at least US\$ 1 million, at least $50 \%$ of the shares are sought in the takeover, and the deal has been completed. Furthermore, the acquirers need to be publicly traded companies from countries where Hofstede (2001) data are available. Finally, we only select those firms for which we obtain daily stock price and firm size data from Thompsen Datastream. This provides us with a final sample of 25,847 acquisitions made by 7,681 firms from 39 countries.

In Table 1, we report some summary statistics of our sample per country. The first and second columns report the number of acquisitions and the number of acquirers originating from a particular country. The number of acquisitions are the largest for the US $(17,757$ acquisitions), covering nearly $70 \%$ of all acquisitions, followed by Canada, Japan and the UK. These are also the countries with the largest number of acquirers. The smallest number of acquisitions is from emerging markets, such as the Philippines, Hungary and Thailand. Acquiring firms from less developed markets appear to be smaller, with the smallest average firm size in the Philippines at US\$272 million, although interestingly the largest firms, on average, are from Spain at US\$25 billion. The smallest average deal size is for Hungary at US\$35 million, while the largest is for France at US\$808 million.

\section{INSERT TABLE 1 HERE}

In column 5 of Table 1 , we report the average CARs for the -1 to 1 day window for each country. In most countries, we find that the average CARs are positive, and CARs are highest in the Philippines at $4.60 \%$ and lowest in Argentina at $-1.08 \%$. 
The last column of Table 1 reports the Hofstede (2001) uncertainty avoidance score for each country. There is a wide variation in the degree of uncertainty avoidance per country. The most uncertainty avoiding nations, according to Hofstede (2001), are Greece and Portugal, while the least uncertainty avoiding countries are Singapore, Hong Kong and Sweden.

\section{INSERT TABLE 2 HERE}

In Table 2 we report summary statistics for our sample over time. In the first column of Table 2 we report the number of takeovers per year. Over time we observe an increase in the number of takeovers, with a spike in the number of takeovers in the years 1997-2000 (which to some extent may be driven by the large merger wave in the US over this period). The final year shows a drop in the number of takeovers. However, this is due to the fact that our sample ends in August 2008. The next column shows the average cumulative abnormal return per year. Although we do not observe any discernable trend in CARs, we do note that CARs are positive for all years. CARs seem to be most depressed in 1990, 1991 and during the merger wave from 1997-2001, an observation which is in line with Moeller et al. (2005). The next two columns of Table 2 report the average deal size and average acquiring firm size (in millions of US dollars). As with CARs there is no clear trend although again we note a spike in both deal and firm size during the 1997-2001 merger wave.

\section{Empirical Findings}

\subsection{Number of Deals and Uncertainty Avoidance}

As a first step in establishing the link between risk aversion and uncertainty avoidance we perform several preliminary tests. We start by investigating the link between the number of 
acquisitions made and the uncertainty avoidance score. Based on our model, we expect a negative relationship between the degree of uncertainty avoidance and the number of acquisitions. If more risk averse managers require higher premiums on takeovers, then we also expect them to engage in fewer takeovers, because there are fewer takeovers offering the required net synergies. We test this hypothesis by estimating the following regression:

$$
N U M_{i j}=\alpha+\beta_{1} U A_{j}+\beta_{2} D_{-} E m_{j}+\varepsilon_{i j}
$$

where $N U M_{i j}$ is the total number of acquisitions made by firm $i$ from country $j$ over the sample period, $U A_{j}$ is the Hofstede (2001) uncertainty avoidance score for country $j$, and $D_{-} E m_{j}$ is an emerging markets dummy. Since $N U M_{i j}$ is count variable we cannot use OLS to estimate equation (11), but use a Poisson regression.

\section{INSERT TABLE 3 HERE}

In the first column of Table 3, we report the results of regression (11), where we report robust t-statistics (in parentheses), controlling for clustering at the country-level (see Petersen, 2009). The relationship between the number of acquisitions made and the uncertainty avoidance score is negative and highly significant. These results support our argument that more risk-averse managers require higher premiums on takeovers, and, therefore, engage in less takeover activity. To examine the robustness of these results, we extend equation (11) by including industry effects and the average (log) size of the acquiring firm (columns 2 and 3). However, these factors do not affect the significance and direction of the relationship between UA and number of acquisitions. 


\subsection{Diversification and Uncertainty Avoidance}

Our second test follows Amihud and Lev (1981) who argue that more risk-averse CEOs engage in more diversifying takeovers. They operationalize risk aversion by looking at the equity stake of managers in the firm and find a relationship between a higher proportion of equity held by management and diversifying takeovers. We investigate the same issue by linking diversifying takeovers to uncertainty avoidance, and estimate the following relationship,

$$
\text { Divers }_{i j t}=\alpha+\beta_{1} U A_{j}+\beta_{2} \frac{\text { DealSize }_{i j t}}{M V_{i j t}}+\beta_{3} \log \left(M V_{i j t}\right)+\varepsilon_{i j t},
$$

where Divers $_{i j t}$ is an indicator variable equal to 1 if the deal is diversifying, and 0 if it is not. We classify a takeover as diversifying if the acquirer and target have different SIC codes. We look at two separate definitions of a diversifying takeover. We first consider situations where there is a difference in the first four digits of the SIC code (incorporating both major and minor diversification of industry) and second where there is a difference in the first two digits

of the SIC (major diversification). We control for the relative size of the deal $\left(\frac{\text { DealSize }_{i j t}}{M V_{i j t}}\right)$ and the $(\log )$ size of the acquirer $\left(\log \left(M V_{i j t}\right)\right)$. In addition, we control for time effects and industry fixed effects. Since the dependent variable is an indicator variable, we estimate equation (12) as a probit model.

INSERT TABLE 4 HERE 
In the first two columns of Table 4 we show the results for the Panel Probit model, where we control the standard errors for clustering at the country-level (see Petersen, 2009). In the last two columns we estimate the coefficients using the Fama-McBeth (1973) approach, by estimating cross-sectional Probit models for each year. For both Panel Probit and FamaMcBeth we find that uncertainty avoidance is significant for both groups of diversifying takeovers. However, the relationship is stronger for major diversifying takeovers. These results suggest that more risk-averse CEOs (from more uncertainty avoiding nations) engage more in diversifying takeovers confirming the findings of Amihud and Lev (1981) and provide some evidence that uncertainty avoidance captures risk aversion. In addition, the results also show that larger firms engage more in diversifying takeovers (confirmed by both Probit and Fama-McBeth (1973)), while relatively smaller deals are more likely to be diversifying.

Combined, these two results suggest that acquirers from high uncertainty avoiding countries tend to engage in less takeover activity altogether, but when they engage in a takeover, they are more inclined to engage in diversifying takeovers.

\subsection{CARs and Uncertainty Avoidance}

The model developed in section 2 posits a positive relationship between risk aversion (measured by uncertainty avoidance) and net synergies (measured by CARs around the announcement of a takeover). We assess this relationship by regressing CARs on uncertainty avoidance scores. However, besides uncertainty avoidance, other factors may affect CARs around takeovers. First, we control for the relative size of the deal (computed as deal size divided by market value of the acquiring firm). Second, we control for (the log of) the size of the acquiring firm (measured in millions of US dollars), because small firms typically make 
acquisitions that result in higher CARs (see Moeller et al., 2004). Third, we control for whether a takeover was diversifying or not. We do this at two levels: 1) by controlling for country diversification (i.e. whether an acquisition was made in a foreign country); and 2) By controlling for industry diversification (based on difference in 2-digit SIC codes). Fourth, we control for the number of prior acquisitions made by the firm as CEOs may learn over time, and this may affect the net synergies on subsequent takeovers. Fifth, we add the three remaining Hofstede (2001) cultural measures, IND, PD and MAS to examine whether other cultural aspects could explain CARs. ${ }^{4}$ Finally, we control for time effects, by including year dummies, as CARs are shown to vary over time (see e.g. Moeller et al., 2005 and Table 2). In addition, we include industry dummies, because Mulherin and Boone (2000) document significant industry clustering in acquisition and divestitures activity.

\section{INSERT TABLE 5 HERE}

Table 5 reports the regression results for CARs (in percentages) on uncertainty avoidance, where we include the different control variables incrementally. For all regressions, we compute robust standard errors controlling for clustering at the country level (see Petersen, 2009). Column 1 reports the regression results where we only include uncertainty avoidance, relative deal size and acquiring firm size. Uncertainty avoidance has the expected positive sign, i.e. CARs are positively related to the degree of uncertainty avoidance of a nation, and a coefficient value of 0.018 . This finding is highly significant, providing strong evidence for our theoretical motivation. Moreover, this finding is also economically significant. As seen in

\footnotetext{
${ }^{4}$ IND (Individualism) reflects the degree to which a society emphasizes the role of the individual as opposed to that of the group; PD (Power distance) refers to the extent to which people believe that power and status are distributed unequally and the extent to which they accept an unequal distribution of power as the proper way of organizing social systems; MAS (Masculinity) refers to the extent to which a society emphasizes traditional masculine values such as competitiveness, assertiveness, achievement, ambition and the acquisition of money and other material possessions, versus feminine values such as nurturing, helping others, not showing off and caring for the quality of life.
} 
Table 1, uncertainty avoidance scores range from 8 to 112 , more than a 100 point difference. In our model this translates to more than a $1.8 \%$ difference in CARs between the most and least uncertainty avoiding countries. Relative deal size is positively related to CAR implying that relatively larger deals provide greater CARs. This may be linked back to our framework, as the consequences for the $\mathrm{CEO}$ of getting a relatively large deal wrong may be greater than the consequences of getting a small deal wrong. Hence larger deals should carry a greater risk premium and should therefore result in a greater CAR. Finally, we find a negative and significant relationship between the size of the acquiring firm and CARs, i.e. larger firms have lower CARs on the takeover announcement. Again, this can be linked back to our model, as we may expect that an unsuccessful takeover may be more consequential for a small firm than for a large firm. The next variables that we consider are our diversification measures. We find that country diversification is positively related to CARs while industry diversification is insignificant. This suggests that acquiring abroad generates higher net synergies. However, inclusion of these variables does not affect the other relationships in a material way.

The next three columns include the time effects and industry effects separately and jointly. Although the inclusion of these variables affects the $R^{2}$ of the regression, it does not affect the magnitude and significance of the other coefficients. Next, we include a variable for the number of prior acquisitions. As noted by Aktas et al. (2009), CEOs may learn about the distribution of possible outcomes from a deal in the process of undertaking acquisitions. This reduces the uncertainty of future deals, and so reduces the risk premium CEOs require when undertaking future acquisitions. Accordingly, CARs should decrease as CEOs undertake more deals. Alternatively, it could be argued that CEO's become better at identifying the synergy gains from deals, and so would only pursue deals with higher CARs. This would lead 
to a positive relationship between CARs and prior acquisitions. The results in column 6 of Table 5 show a positive and significant relationship between number of prior acquisitions and the CARs earned in a deal. This suggests that CEOs become better at identifying target companies that could generate synergies and therefore pick better deals. Finally, we add the other Hofstede (2001) cultural dimensions to the regression model, to see if other cultural aspects affect CARs. We find that the masculinity score has a significant negative impact on CARs, while power distance has a weakly significant negative impact. The results for all other variables remain unchanged.

\subsection{Robustness Tests}

To assess the robustness of these findings we proceed in two ways. First, we estimate the previous regression following Fama and McBeth (1973). These Fama-McBeth results are presented in Table 6. Broadly speaking, these results are in line with the reported Clustered OLS results, supporting the hypothesis that risk aversion affects CARs. Most of the control variables also remain unchanged with the exception of prior acquisitions which loses significance in these models. Further, we observe that individualism, rather than masculinity and power distance becomes significant.

\section{INSERT TABLE 6 HERE}

Second, we investigate various sub-samples and report results in Table 7. First, we split our sample into pre- and post-2000 to examine whether our findings are robust over time. Columns 1 and 2 show that uncertainty avoidance is significant only in the second subsamples. Furthermore, there are some notable differences in the control variables, e.g. relative deal size has a coefficient twice the size in the earlier sub-sample; industry diversification is 
significant in the early part of the sample; and prior acquisitions changes sign pre- and post2000. Second, we exclude the US from the sample. We do this because takeovers originating from the US make up nearly $70 \%$ of the total sample, and so the results reported in Table 5 , may be driven by the US. In column 3 of Table 7, we report the regression results for the model excluding the US. We note that the sample size decreases considerably to 8,291 takeovers. However, we find that the coefficient on uncertainty avoidance remains unchanged, showing that uncertainty avoidance is not a US effect. Most of the significance of other variables remain unchanged as well, except for prior acquisitions, which becomes insignificant after dropping the US.

\section{INSERT TABLE 7 HERE}

Third, we split our sample into developed and emerging markets. In our sample, we have 26 developed nations and 13 emerging nations. We report the results for the two sub-samples in the fourth and fifth columns of Table 7. For the developed markets, we find that the results are relatively unchanged compared with the results reported in Table 5. For emerging markets, uncertainty avoidance becomes insignificant, indicating that uncertainty avoidance does not play a role in these markets. However, we note that the sample size for emerging markets is considerably smaller with 545 acquisitions.

\subsection{Further Extensions}

According to our model, larger deals could lead to larger gains for the CEO, but also to larger losses. If risk aversion affects the CEO's decision making, then larger deals should carry a higher premium than smaller deals. Moreover, the premium for larger deals should be a function of the level of risk aversion. We explore this issue in two ways. First, we create 
quartiles based on the log of deal size and construct four new uncertainty avoidance variables. $U A_{l}$ is equal to the country's uncertainty avoidance score for the acquiring firm if the deal size was in the smallest quartile and zero otherwise. We define $U A_{2}, U A_{3}$, and $U A_{4}$ similarly. Next, we perform a regression where we replace the uncertainty avoidance score with our four new variables.

\section{INSERT TABLE 8 HERE}

In the first two columns of Table 8 we present the results for the interaction between absolute deal size and uncertainty avoidance. In the first column we present the results for Clustered OLS with clustered standard errors, in the second column we report the results for the FamaMcBeth (1973) approach. For Clustered OLS, we find that uncertainty avoidance is significant in all quartiles and, apart from the last quartile, coefficients increase for the larger deciles. Therefore, as predicted by our model, the importance of uncertainty avoidance increases when the size of the deal becomes larger. Furthermore, individual Wald tests on the Clustered OLS show that the differences between quartiles are significant for $\mathrm{UA}_{1}$ and $\mathrm{UA}_{2}$, $\mathrm{UA}_{2}$ and $\mathrm{UA}_{3}$, but not for the coefficients between $\mathrm{UA}_{3}$ and $\mathrm{UA}_{4}$. A joint Wald test confirms that uncertainty avoidance has a significantly different impact for different deal sizes.

The next column shows the results for the same model using the Fama-McBeth (1973) estimation procedure. The results are supportive of the Clustered OLS results. We see a similar pattern of the increasing importance of uncertainty avoidance as deal sizes increase. However, according to our Fama-McBeth results, uncertainty avoidance does not play a role for the smallest quartile. 
The second way in which we explore the interaction between deal size and risk aversion is by employing the relative deal size. We use the same approach as absolute deal size to create quartiles and conduct the same tests as above. In columns 3 and 4 of Table 8 we report the results for these regressions. In column 3, we report the results for the Clustered OLS. The results are broadly in line with our earlier findings. Uncertainty avoidance plays no role for the smallest quartile and there is an increasing trend in the importance of uncertainty avoidance between $\mathrm{UA}_{2}$ and $\mathrm{UA}_{4}$. However, we do note that the impact of uncertainty avoidance on CAR is negative for the second quartile. The results for the control variables are unchanged compared with column 1 . Wald tests again support the notion that uncertainty avoidance has a significantly different impact as the relative size of the deal to the firm increases. Again the Fama-McBeth (1973) results support the clustered OLS findings. However, the significance of $\mathrm{UA}_{2}$ disappears.

\section{Conclusion}

Prior research suggests that culture has an impact on the risk aversion of people within a country (e.g. Chui and Kwok, 2008) and affects managerial decision making (e.g. Geletkanycz, 1997). One important decision made by the top management of the firm is the decision to take over another firm. In this paper, we argue that since takeovers are a risk to the firm's equity, and since the CEO is disproportionally exposed to this risk, a risk-averse CEO will require a compensation for taking this risk. With compensation of the CEO tied to the net synergies gained in the takeover, a more risk-averse CEO will only engage in a takeover if the expected net synergies are large enough. We argue that behavioral traits, such as risk aversion, are shared by members of a society and use uncertainty avoidance as defined by Hofstede (2001) as a proxy for risk aversion. Using a sample of 25,843 takeovers from 39 
countries, we find that more risk-averse CEOs engage in less takeover activity. Additionally, we confirm the findings of previous work that shows that a more risk-averse manager engages in more diversifying takeovers. In line with our theoretical model, net synergies, approximated by the CARs around the takeover announcement, are positively related to the degree of uncertainty avoidance of a country. This finding is not only statistically significant but also economically so. These results are robust to the addition of various controls, different estimation techniques and across various subsamples (although we find no relationship in the early part of our sample). In line with our prediction we also find that the relative size of a deal is an important determinant of CAR, and when exploring whether deal size interacts with risk aversion, we find that risk aversion has small or even insignificant role for relatively small deals, whereas it becomes more important for large deals. 


\section{References}

Aktas, N., de Bodt, E. and Roll, R. (2009). Learning, hubris and corporate serial acquisitions. Journal of Corporate Finance 15, 543-561.

Amihud, Y. and Lev, B. (1981). Risk reduction as a managerial motive for conglomerate mergers. Bell Journal of Economics 12, 605-617.

Beugelsdijk, S. and Frijns, B. (2010). A cultural explanation of the foreign bias in international asset allocation. Journal of Banking and Finance 34, 2121-2131.

Bushman, R., Piotroski, J. and Smith, A. (2003). What determines corporate transparency? Journal of Accounting Research 42, 207-252.

Chan, K., Covrig, V. and Ng, L. (2005). What determines the domestic bias and foreign bias? Evidence from mutual fund equity allocations worldwide. Journal of Finance 60, 1495-1534.

Chui, A. and Kwok, C. (2008). National culture and life insurance consumption. Journal of International Business Studies 39, 88-101.

Chui, A., Titman, S. and Wei, K. (2010). Individualism and momentum around the world. Journal of Finance, Forthcoming.

Doidge, C., G. Karolyi, and Stulz, R. (2007). Why do countries matter so much for corporate governance? Journal of Financial Economics 86, 1-39.

Fama, E. and McBeth, J. (1973). Risk, return and equilibrium: Empirical tests. Journal of Political Economy 81, 607-636.

Geletkanycz, M. (1997). The salience of 'culture's consequences': The effects of cultural values on top executive commitment to the status quo. Strategic Management Journal 18, 615-634.

Graham, J., Harvey, C. and Puri, M. (2009). Managerial Attitudes and Corporate Actions. Working Paper, Duke University.

Halek, M., and Eisenhauer, J. (2001). Demography of risk aversion. Journal of Risk and Insurance 68, 1-24.

Hall, B. and Murphy, K. (2002). Stock options for underdiversified executives. Journal of Accounting and Economics 33, 3-42.

Hilary, G. and Hui, K. (2009), Does religion matter in corporate decision making in America? Journal of Financial Economics 93, 474-489.

Hofstede, G. (2001). Culture's Consequences: International Differences in Work-Related Values. Sage Publications: Beverly Hills, CA, $2^{\text {nd }}$ edition.

Jensen, M. and Meckling, W. (1976). Theory of the firm: managerial behavior, agency costs and ownership structure. Journal of Financial Economics 3, 305-360. 
Kirkman, B., Lowe, K. and Gibson, C. (2006). A quarter century of Culture's Consequences: A review of empirical research incorporating Hofstede's cultural values framework. Journal of International Business Studies 37, 285-320.

Kwok, C. and Tadesse, S. (2006). National culture and financial systems. Journal of International Business Studies 37, 227-247.

La Porta, R., Lopez-de-Silanes, F., Shleifer, A., and Vishny, R. (1998). Law and Finance, Journal of Political Economy 52, 1113-1155.

La Porta, R., Lopez-de-Silanes, F., Shleifer, A., and Vishny, R. (1999). Corporate ownership around the world. Journal of Finance 54, 471-517.

La Porta, R., Lopez-de-Silanes, F., Shleifer, A., and Vishny, R. (2000). Agency problems and dividend policies around the world. Journal of Finance 55, 1-33.

La Porta, R., Lopez-de-Silanes, F., Shleifer, A., and Vishny, R. (2006). What works in securities laws. Journal of Finance 61, 1-32.

Lehn, K. and Zhao, M. (2006). CEO Turnover after Acquisitions: Are Bad Bidders Fired? Journal of Finance 61, 1759-1811.

Lewellen, K. (2006). Financing decisions when managers are risk averse. Journal of Financial Economics 82, 551-589.

Licht, A., Goldschmidt, C., and Schwartz, S. (2005). Culture, law and corporate governance. International Review of Law and Economics 25, 229-255.

May, D. (1995). Do managerial motives influence firm risk reduction strategies? Journal of Finance 50, 1291-1308.

Moeller, S., Schlingemann, F. and Stulz, R. (2004). Firm size and gains from acquisitions. Journal of Financial Economics 73, 201-228.

Moeller, S., Schlingemann, F. and Stulz, R. (2005). Wealth destruction on a massive scale? A study of acquiring-firm returns in the recent merger wave. Journal of Finance 60, 757-782.

Morck, R., Shleifer, A., and Vishny, R. (1990). Do managerial objectives drive bad acquisitions? The Journal of Finance 45, 31-47.

Mueller, D., and Yurtoglu, B. (2007). Corporate governance and the returns to acquiring firms' shareholders: an international comparison. Managerial and Decision Economics 28, 879-896.

Mulherin, J., and Boone, A. (2000). Comparing acquisitions and divestitures. Journal of Corporate Finance 6, 117-139.

Petersen, M. (2009). Estimating Standard Errors in Finance Panel Data Sets: Comparing Approaches. Review of Financial Studies 22, 435-480.

Pratt, J. (1964). Risk Aversion in the Small and in the Large. Econometrica 32, 122-136. 
Seth, A., Song, K., and Pettit, R. (2000). Synergy, managerialism or hubris? An empirical examination of motives for foreign acquisitions of U.S. firms. Journal of International Business Studies 31, 387-405.

Stulz, R. and Williamson, R. (2003). Culture, openness and finance. Journal of Financial Economics 70, 313-349.

Tosi, H. and Greckhamer, T. (2004). Culture and CEO Compensation. Organization Science $15,657-670$.

Weber, M. (1905). The Protestant Ethic and the Spirit of Capitalism. Allen \& Unwin, London. 
Table 1: Summary Statistics per Country

This table reports summary statistics per country on the firms and acquisitions included in our sample for the period January 1990 to August 2008. Number of Acquisitions is the total number of acquisitions per country; Number of Acquirers is the total number of acquirers per country; Firm Size is the average market value of the acquiring firms (in millions of US dollars); Deal Size is the value of the transaction (in millions of US dollars); CAR $(-1,1)$ is the cumulative return over the period one day before the announcement to one day after the announcement; and Uncertainty Avoidance is the uncertainty avoidance score of Hofstede (2001).

\begin{tabular}{|c|c|c|c|c|c|c|}
\hline Country & $\begin{array}{r}\text { Number of } \\
\text { Acquisitions }\end{array}$ & $\begin{array}{r}\text { Number of } \\
\text { Acquirers } \\
\end{array}$ & $\begin{array}{c}\text { Firm } \\
\text { Size } \\
\end{array}$ & Deal Size & $\operatorname{CAR}(-1,1)$ & $\begin{array}{r}\text { Uncertainty } \\
\text { Avoidance }\end{array}$ \\
\hline Argentina & 20 & 9 & 1,898 & 173 & $-1.08 \%$ & 86 \\
\hline Australia & 1,142 & 402 & 1,703 & 111 & $1.60 \%$ & 51 \\
\hline Austria & 53 & 24 & 2,559 & 283 & $-0.02 \%$ & 70 \\
\hline Belgium & 82 & 28 & 5,605 & 322 & $1.85 \%$ & 94 \\
\hline Brazil & 28 & 14 & 2,252 & 478 & $2.44 \%$ & 76 \\
\hline Canada & 1,758 & 662 & 1,537 & 173 & $1.16 \%$ & 48 \\
\hline Chile & 24 & 18 & 1,767 & 139 & $2.96 \%$ & 86 \\
\hline China & 48 & 37 & 1,364 & 50 & $-1.06 \%$ & 30 \\
\hline Czech Rep. & 11 & 4 & 8,016 & 309 & $-0.74 \%$ & 74 \\
\hline Finland & 199 & 56 & 9,713 & 186 & $1.53 \%$ & 59 \\
\hline France & 444 & 176 & 7,236 & 809 & $1.17 \%$ & 86 \\
\hline Germany & 431 & 150 & 19,724 & 805 & $0.49 \%$ & 65 \\
\hline Greece & 19 & 13 & 2,363 & 167 & $1.33 \%$ & 112 \\
\hline Hong Kong & 229 & 135 & 2,275 & 184 & $-0.12 \%$ & 29 \\
\hline Hungary & 6 & 2 & 1,681 & 36 & $-0.27 \%$ & 82 \\
\hline India & 97 & 51 & 2,978 & 105 & $0.36 \%$ & 40 \\
\hline Indonesia & 13 & 10 & 1,026 & 110 & $1.02 \%$ & 48 \\
\hline Ireland & 215 & 34 & 2,519 & 87 & $0.92 \%$ & 35 \\
\hline Israel & 30 & 14 & 623 & 53 & $2.28 \%$ & 81 \\
\hline Italy & 206 & 84 & 3,861 & 170 & $0.74 \%$ & 75 \\
\hline Japan & 1,217 & 629 & 4,054 & 174 & $1.34 \%$ & 92 \\
\hline Malaysia & 81 & 51 & 478 & 82 & $0.56 \%$ & 36 \\
\hline Mexico & 14 & 5 & 4,543 & 387 & $-0.52 \%$ & 82 \\
\hline Netherlands & 192 & 51 & 7,297 & 419 & $0.77 \%$ & 53 \\
\hline New Zealand & 85 & 39 & 736 & 90 & $0.60 \%$ & 49 \\
\hline Norway & 133 & 55 & 985 & 58 & $1.98 \%$ & 50 \\
\hline Philippines & 5 & 5 & 273 & 100 & $4.60 \%$ & 44 \\
\hline Poland & 42 & 18 & 733 & 94 & $0.41 \%$ & 93 \\
\hline Portugal & 21 & 12 & 2,298 & 110 & $0.66 \%$ & 104 \\
\hline Singapore & 128 & 85 & 991 & 91 & $-0.07 \%$ & 8 \\
\hline South Africa & 167 & 81 & 1,030 & 118 & $2.11 \%$ & 49 \\
\hline South Korea & 129 & 90 & 2,502 & 187 & $2.92 \%$ & 85 \\
\hline Spain & 15 & 12 & 25,578 & 232 & $1.56 \%$ & 86 \\
\hline Sweden & 231 & 81 & 2,221 & 124 & $1.83 \%$ & 29 \\
\hline Switzerland & 36 & 21 & 716 & 64 & $3.25 \%$ & 58 \\
\hline Taiwan & 53 & 39 & 2,933 & 299 & $-1.00 \%$ & 69 \\
\hline Thailand & 8 & 6 & 467 & 101 & $0.09 \%$ & 64 \\
\hline United Kingdom & 768 & 202 & 4,921 & 109 & $1.05 \%$ & 35 \\
\hline United States & 17,522 & 4,276 & 7,182 & 264 & $0.62 \%$ & 46 \\
\hline
\end{tabular}


Table 2: Summary Statistics per Country

This table reports summary statistics for different takeover characteristics per year. Number of Takeovers is the total number of takeovers per year for all countries in the sample; $\operatorname{CAR}(-1,1)$ is the average cumulative return per year over the period one day before the announcement to one day after the announcement; Average Deal Size is the average value of the transaction per year (in millions of US dollars); and Average Firm Size is the average size of the acquirer per year (in millions of US dollars).

\begin{tabular}{ccccc}
\hline \hline Year & $\begin{array}{c}\text { Number of } \\
\text { Takeovers }\end{array}$ & CAR(-1, 1) & Average Deal Size & Average Firm Size \\
\hline 1990 & 350 & $0.42 \%$ & 151.04 & $3,512.76$ \\
1991 & 382 & $0.32 \%$ & 99.34 & $2,254.36$ \\
1992 & 461 & $1.36 \%$ & 85.28 & $1,771.66$ \\
1993 & 642 & $1.10 \%$ & 110.01 & $1,909.75$ \\
1994 & 845 & $0.67 \%$ & 101.28 & $2,314.97$ \\
1995 & 976 & $0.60 \%$ & 203.27 & $2,228.69$ \\
1996 & 1,375 & $1.15 \%$ & 165.14 & $2,423.24$ \\
1997 & 1,830 & $0.69 \%$ & 175.59 & $2,992.66$ \\
1998 & 2,162 & $0.49 \%$ & 272.65 & $4,226.37$ \\
1999 & 1,863 & $0.78 \%$ & 415.34 & $10,083.72$ \\
2000 & 1,880 & $0.51 \%$ & 395.14 & $14,292.04$ \\
2001 & 1,581 & $0.56 \%$ & 294.17 & $8,082.11$ \\
2002 & 1,568 & $1.18 \%$ & 185.53 & $5,296.69$ \\
2003 & 1,570 & $0.70 \%$ & 203.20 & $4,894.09$ \\
2004 & 1,849 & $0.95 \%$ & 239.58 & $5,885.20$ \\
2005 & 2,112 & $1.07 \%$ & 308.06 & $6,153.22$ \\
2006 & 2,016 & $0.84 \%$ & 273.62 & $6,138.15$ \\
2007 & 1,838 & $0.93 \%$ & 301.37 & $8,766.68$ \\
2008 & 608 & $0.62 \%$ & 139.04 & $10,308.07$ \\
\hline \hline
\end{tabular}




\section{Table 3: Number of Deals and Uncertainty Avoidance}

This table reports results for the Poisson regression. We regress the number of deals per company on uncertainty avoidance and several control variables. Number of Deals is measured as the total number of deals made by one acquiring firm over the sample period January 1990 to August 2008. Uncertainty Avoidance is the uncertainty avoidance score of Hofstede (2001); Emerging is an emerging markets dummy, equal to 1 if the firm is from an emerging markets; Log Av. Market Cap. is the natural log of the average market capitalization of the acquiring form over time; and Industry Effects are dummies that are equal to 1 if the firm is from a specific industry (measured by the 2-digit SIC code). We report t-statistics in parentheses and indicate significance at the $10 \%$, $5 \%$, and $1 \%$ levels by $* * *, * * *$, respectively.

\begin{tabular}{lrrr}
\hline \hline & $(1)$ & $(2)$ & $(3)$ \\
\hline Uncertainty Avoidance & $-0.0096^{* * *}$ & $-0.0092^{* * *}$ & $-0.0112^{* * *}$ \\
& $(-2.70)$ & $(-2.83)$ & $(-4.18)$ \\
Emerging & $-0.6033^{* * *}$ & $-0.6009^{* * *}$ & $-0.5058^{* * *}$ \\
& $(-4.22)$ & $(-4.35)$ & $(3.61)$ \\
Log Av. Market Cap. & & & $0.2448^{* * *}$ \\
& & & $(20.33)$ \\
Industry Effects & $\mathrm{NO}$ & $\mathrm{YES}$ & YES \\
$\mathrm{N}$ & 7,681 & 7,681 & 7,681 \\
\hline \hline
\end{tabular}




\section{Table 4: Diversification and Uncertainty Avoidance}

This table reports results for the Probit regression. We report Probit regression results for diversification dummy variables on uncertainty avoidance and several controls. The 4-digit (2-digit) diversification dummies is equal to 1 if the acquiring firm conducts a takeovers of firm that is outside its own industry, measured by the difference in the 4-digit (2-digit) SIC code. The diversification variable based on 4-digit SIC codes measure all diversifying takeover activity, whereas the diversification variable based on 2-digit SIC codes measures major diversifying takeover activity. Uncertainty Avoidance is the uncertainty avoidance score of Hofstede (2001); Rel. Deal Size is computed as the size of the deal divided by the market capitalization of the firm; Log Market Cap. is the natural logarithm of the size of the acquiring firm (measured in US dollars); Time Effects are dummies equal to one if the takeover took place in a given year and zero otherwise; and Industry Effects are dummies that are equal to 1 if the firm is from a specific industry (measured by the 2-digit SIC code). The first two columns report Clustered - Probit results, where we compute robust standard errors controlling for clustering at the country level. The last two columns report the Fama-McBeth (1973) estimator based on probit regressions for each year. We report t-statistics in parentheses and indicate significance at the 10\%, 5\%, and 1\% levels by $*, * *, * * *$, respectively.

\begin{tabular}{|c|c|c|c|c|}
\hline & \multicolumn{2}{|c|}{ Clustered - Probit } & \multicolumn{2}{|c|}{ Fama-McBeth } \\
\hline & 4-digit SIC & 2-digit SIC & 4-digit SIC & 2-digit SIC \\
\hline \multirow[t]{2}{*}{ Uncertainty Avoidance } & $0.0034 *$ & $0.0038 * *$ & $0.0025^{*}$ & $0.0038 * *$ \\
\hline & $(1.75)$ & $(2.15)$ & (1.90) & (2.59) \\
\hline \multirow[t]{2}{*}{ Rel. Deal Size } & $-0.125 * * *$ & $-0.148 * * *$ & -0.005 & -0.040 \\
\hline & $(-3.45)$ & $(-3.13)$ & $(-0.19)$ & $(-1.61)$ \\
\hline \multirow[t]{2}{*}{ Log Market Cap. } & $0.012 * * *$ & $0.015 * * *$ & $0.032 * * *$ & $0.039 * * *$ \\
\hline & $(2.77)$ & $(2.71)$ & $(3.15)$ & $(4.22)$ \\
\hline Time Effects & YES & YES & - & - \\
\hline Industry Effects & YES & YES & YES & YES \\
\hline $\mathrm{N}$ & 25,741 & 25,741 & & \\
\hline
\end{tabular}




\section{Table 5: Cumulative Abnormal Returns and Uncertainty Avoidance}

This table reports results for clustered OLS regressions of the Cumulative Abnormal Returns (CARs) around takeover announcements over the period 1990-2008 on uncertainty avoidance and various control variables. CARs are measured as the average cumulative return over the period one day before the announcement to one day after the announcement. Uncertainty Avoidance is the uncertainty avoidance score of Hofstede (2001); Rel. Deal Size is computed as the size of the deal divided by the market capitalization of the firm; Log Market Cap. is the natural logarithm of the size of the acquiring firm (measured in US dollars); Country Divers. is a dummy variable equal to 1 if the acquiring firm conducts a takeovers of firm that is outside its own country; Industry Divers. is a dummy variable equal to 1 if the acquiring firm conducts a takeovers of firm that is outside its own industry, measured by the difference in the 2-digit SIC code; Prior Acquisitions is a dummy variable equal to 1 if the firm has already conducted a takeover before in our sample period; IND is the individualism score of Hofstede (2001); PD is the power distance score of Hofstede (2001); MAS is the masculinity score of Hofstede (2001); Time Effects are dummies equal to one if the takeover took place in a given year and zero otherwise; and Industry Effects are dummies that are equal to 1 if the firm is from a specific industry (measured by the 2-digit SIC code). We compute robust standard errors controlling for clustering at the country level and report tstatistics in parentheses. Significance at the $10 \%, 5 \%$, and $1 \%$ levels are indicated by *,**, ***, respectively.

\begin{tabular}{|c|c|c|c|c|c|c|c|}
\hline & $(1)$ & (2) & (3) & (4) & $(5)$ & (6) & (7) \\
\hline \multirow[t]{2}{*}{ Uncertainty Avoidance } & $0.016 * * *$ & $0.015 * * *$ & $0.015 * * *$ & $0.014 * * *$ & $0.013 * * *$ & $0.014 * * *$ & $0.021 * * *$ \\
\hline & $(6.26)$ & $(6.08)$ & $(5.98)$ & (4.99) & $(4.95)$ & $(5.18)$ & $(7.86)$ \\
\hline \multirow[t]{2}{*}{ Rel. Deal Size } & $0.668 * * *$ & $0.670 * * *$ & $0.669 * * *$ & $0.658 * * *$ & $0.660 * * *$ & $0.659 * * *$ & $0.653 * * *$ \\
\hline & $(4.29)$ & $(4.23)$ & $(4.04)$ & $(4.64)$ & $(4.42)$ & $(4.40)$ & $(4.41)$ \\
\hline \multirow[t]{2}{*}{ Log Market Cap. } & $-0.348 * * *$ & $-0.359 * * *$ & $-0.359 * * *$ & $-0.353 * * *$ & $0.353 * * *$ & $-0.365 * * *$ & $-0.366 * * *$ \\
\hline & $(-10.69)$ & $(-9.68)$ & $(-9.50)$ & $(-10.73)$ & $(-9.99)$ & $(-10.41)$ & $(-10.48)$ \\
\hline \multirow[t]{2}{*}{ Country Divers. } & & $0.427 * * *$ & $0.428 * * *$ & $0.316^{*}$ & $0.321 *$ & $0.325^{*}$ & 0.291 \\
\hline & & $(3.12)$ & $(3.17)$ & $(1.79)$ & $(1.84)$ & $(1.88)$ & (1.67) \\
\hline \multirow[t]{2}{*}{ Industry Divers. } & & -0.087 & $-0.089 *$ & -0.082 & -0.086 & -0.088 & -0.073 \\
\hline & & $(-1.58)$ & $(-1.69)$ & $(-1.21)$ & $(-1.32)$ & $(-1.35)$ & $(-1.08)$ \\
\hline \multirow[t]{2}{*}{ Prior Acquisitions } & & & & & & $0.009 * * *$ & $0.008 * *$ \\
\hline & & & & & & $(2.93)$ & $(2.11)$ \\
\hline \multirow[t]{2}{*}{ IND } & & & & & & & 0.004 \\
\hline & & & & & & & $(1.03)$ \\
\hline \multirow[t]{2}{*}{ PD } & & & & & & & $-0.010^{*}$ \\
\hline & & & & & & & $(-1.80)$ \\
\hline \multirow[t]{2}{*}{ MAS } & & & & & & & $-0.009 * *$ \\
\hline & & & & & & & $(-2.62)$ \\
\hline Time Effects & $\mathrm{NO}$ & NO & YES & NO & YES & YES & YES \\
\hline Industry Effects & NO & NO & $\mathrm{NO}$ & YES & YES & YES & YES \\
\hline $\mathrm{N}$ & 25,750 & 25,750 & 25,750 & 25,750 & 25,750 & 25,750 & 25,750 \\
\hline $\mathrm{R}^{2}$ & 0.0162 & 0.0170 & 0.0182 & 0.0234 & 0.0246 & 0.0247 & 0.0252 \\
\hline
\end{tabular}


Table 6: Cumulative Abnormal Returns and Uncertainty Avoidance (Fama-McBeth)

This table reports Fama-McBeth results for the Cumulative Abnormal Returns (CAR) around takeover announcements over the period 1990-2008 on uncertainty avoidance and various control variables. CARs are measured as the average cumulative return over the period one day before the announcement to one day after the announcement. Uncertainty Avoidance is the uncertainty avoidance score of Hofstede (2001); Rel. Deal Size is computed as the size of the deal divided by the market capitalization of the firm; Log Market Cap. is the natural logarithm of the size of the acquiring firm (measured in US dollars); Country Divers. is a dummy variable equal to 1 if the acquiring firm conducts a takeovers of firm that is outside its own country; Industry Divers. is a dummy variable equal to 1 if the acquiring firm conducts a takeovers of firm that is outside its own industry, measured by the difference in the 2-digit SIC code; Prior Acquisitions is a dummy variable equal to 1 if the firm has already conducted a takeover before in our sample period; IND is the individualism score of Hofstede (2001); PD is the power distance score of Hofstede (2001); MAS is the masculinity score of Hofstede (2001); and Industry Effects are dummies that are equal to 1 if the firm is from a specific industry (measured by the 2digit SIC code). We compute robust standard errors controlling for clustering at the country level and report tstatistics in parentheses. Significance at the $10 \%, 5 \%$, and $1 \%$ levels are indicated by $*, * *, * * *$, respectively.

\begin{tabular}{lrrrrr}
\hline \hline & $(1)$ & $(2)$ & $(3)$ & $(4)$ & $(5)$ \\
\hline Uncertainty Avoidance & $0.009^{* * *}$ & $0.008^{* * *}$ & $0.010^{* * *}$ & $0.010^{* * *}$ & $0.016^{* * *}$ \\
& $(2.83)$ & $(2.82)$ & $(3.31)$ & $(3.19)$ & $(5.69)$ \\
Rel. Deal Size & $0.692^{* * *}$ & $0.694^{* * *}$ & $0.589^{* * *}$ & $0.579^{* * *}$ & $0.575^{* *}$ \\
& $(3.27)$ & $(3.30)$ & $(2.72)$ & $(2.69)$ & $(2.64)$ \\
Log Market Cap. & $-0.363^{* * *}$ & $-0.370^{* * *}$ & $-0.358^{* * *}$ & $-0.364^{* * *}$ & $-0.363^{* * *}$ \\
& $(-9.11)$ & $(-9.91)$ & $(-10.89)$ & $(-10.79)$ & $(-10.70)$ \\
Country Divers. & & $0.321^{* * *}$ & $0.195^{*}$ & $0.197^{*}$ & $0.212^{*}$ \\
& & $(2.92)$ & $(1.69)$ & $(1.72)$ & $(1.88)$ \\
Industry Divers. & & -0.123 & -0.195 & $-0.202^{*}$ & -0.175 \\
& & $(-1.34)$ & $(-1.64)$ & $(-1.70)$ & $(-1.49)$ \\
Prior Acqs. & & & -0.027 & -0.035 \\
& & & & $(-1.14)$ & $(-1.32)$ \\
IND & & & & $0.012^{* *}$ \\
& & & & & $(2.22)$ \\
PD & & & & & -0.004 \\
& & & & & $-0.79)$ \\
MAS & & & & & -0.008 \\
Industry Effects & & & & & \\
\hline \hline
\end{tabular}




\section{Table 7: Cumulative Abnormal Returns and Uncertainty Avoidance for Different Sub-Samples}

This table reports results for clustered OLS regressions of the Cumulative Abnormal Returns (CARs) around takeover announcements on uncertainty avoidance and various control variables. CARs are measured as the average cumulative return over the period one day before the announcement to one day after the announcement. Uncertainty Avoidance is the uncertainty avoidance score of Hofstede (2001); Rel. Deal Size is computed as the size of the deal divided by the market capitalization of the firm; Log Market Cap. is the natural logarithm of the size of the acquiring firm (measured in US dollars); Country Divers. is a dummy variable equal to 1 if the acquiring firm conducts a takeovers of firm that is outside its own country; Industry Divers. is a dummy variable equal to 1 if the acquiring firm conducts a takeovers of firm that is outside its own industry, measured by the difference in the 2-digit SIC code; Prior Acquisitions is a dummy variable equal to 1 if the firm has already conducted a takeover before in our sample period; Time Effects are dummies equal to one if the takeover took place in a given year and zero otherwise; and Industry Effects are dummies that are equal to 1 if the firm is from a specific industry (measured by the 2-digit SIC code). Column 1 presents the results for the period 1990-2000; column 2 presents the results for the period 2001-2008; column 3 presents the results for the model excluding the US; column 4 presents the results for the model including only developed markets; and column 5 presents the results for the model including only emerging markets. For all models we compute robust standard errors controlling for clustering at the country level and report t-statistics in parentheses. Significance at the $10 \%, 5 \%$, and $1 \%$ levels are indicated by $*, * *, * *$, respectively.

\begin{tabular}{|c|c|c|c|c|c|}
\hline & $\begin{array}{r}\text { Pre } \\
2000 \\
\end{array}$ & $\begin{array}{c}\text { Post } \\
2000\end{array}$ & $\begin{array}{r}\text { Excluding } \\
\text { US }\end{array}$ & $\begin{array}{r}\text { Developed } \\
\text { Markets } \\
\end{array}$ & $\begin{array}{r}\text { Emerging } \\
\text { Markets }\end{array}$ \\
\hline \multirow[t]{2}{*}{ Uncertainty Avoidance } & 0.007 & $0.016^{* * *}$ & $0.017 * * *$ & $0.014 * * *$ & 0.002 \\
\hline & $(1.32)$ & $(6.04)$ & $(4.79)$ & $(5.09)$ & $(0.18)$ \\
\hline \multirow[t]{2}{*}{ Rel. Deal Size } & $0.900 * * *$ & $0.477 * * *$ & $0.245 * * *$ & $0.686^{* * *}$ & $0.202 * *$ \\
\hline & $(3.20)$ & $(3.78)$ & $(3.42)$ & $(4.66)$ & $(0.35)$ \\
\hline \multirow[t]{2}{*}{ Log Market Cap. } & $-0.284 * * *$ & $-0.417 * * *$ & $-0.633 * * *$ & $-0.361 * * *$ & $-0.655 * *$ \\
\hline & $(-10.91)$ & $(-8.89)$ & $(-6.60)$ & $(-10.59)$ & $(-2.17)$ \\
\hline \multirow[t]{2}{*}{ Country Divers. } & 0.275 & $0.362 * *$ & $0.699 * * *$ & $0.290 *$ & $1.712 * * *$ \\
\hline & $(1.39)$ & $(2.10)$ & $(2.90)$ & $(1.76)$ & $(2.46)$ \\
\hline \multirow[t]{2}{*}{ Industry Divers. } & $-0.171 * *$ & -0.063 & 0.051 & -0.074 & $-1.148 * * *$ \\
\hline & $(-2.00)$ & $(-0.55)$ & $(0.33)$ & $(-1.05)$ & $(-3.78)$ \\
\hline \multirow[t]{2}{*}{ Prior Acquisitions } & $-0.016 * * *$ & $0.020 * * *$ & 0.012 & $0.009 * * *$ & -0.118 \\
\hline & $(-2.85)$ & $(4.88)$ & $(0.59)$ & $(2.78)$ & $(-1.22)$ \\
\hline Time Effects & YES & YES & YES & YES & YES \\
\hline Industry Effects & YES & YES & YES & YES & YES \\
\hline Number of countries included & 38 & 39 & 38 & 26 & 13 \\
\hline $\mathrm{N}$ & 10,795 & 14,955 & 8,291 & 25,205 & 545 \\
\hline $\mathrm{R}^{2}$ & 0.0255 & 0.0296 & 0.0379 & 0.0248 & 0.2027 \\
\hline
\end{tabular}




\section{Table 8: Interaction of Uncertainty Avoidance and Deal Size}

This table reports results for clustered OLS and Fama-McBeth (1973) regressions of the Cumulative Abnormal Returns (CARs) around takeover announcements over the period 1990-2008 on interaction terms of uncertainty avoidance and deals size and various control variables. CARs are measured as the average cumulative return over the period one day before the announcement to one day after the announcement. In the first two columns, $\mathrm{UA}_{1}$ is the uncertainty avoidance score of Hofstede (2001) if the deal size was in the first quartile; $\mathrm{UA}_{2}, \mathrm{UA}_{3}$, and $\mathrm{UA}_{4}$ are defined likewise. In the last two columns, $\mathrm{UA}_{1}$ is the uncertainty avoidance score of Hofstede (2001) if the relative deal size was in the first quartile (relative to the size of the firm); $\mathrm{UA}_{2}, \mathrm{UA}_{3}$, and $\mathrm{UA}_{4}$ are defined likewise. Rel. Deal Size is computed as the size of the deal divided by the market capitalization of the firm; Log Market Cap. is the natural logarithm of the size of the acquiring firm (measured in US dollars); Country Divers. is a dummy variable equal to 1 if the acquiring firm conducts a takeovers of firm that is outside its own country; Industry Divers. is a dummy variable equal to 1 if the acquiring firm conducts a takeovers of firm that is outside its own industry, measured by the difference in the 2-digit SIC code; Prior Acquisitions is a dummy variable equal to 1 if the firm has already conducted a takeover before in our sample period; Time Effects are dummies equal to one if the takeover took place in a given year and zero otherwise; and Industry Effects are dummies that are equal to 1 if the firm is from a specific industry (measured by the 2-digit SIC code). We compute robust standard errors controlling for clustering at the country level and report t-statistics in parentheses. Significance at the $10 \%, 5 \%$, and $1 \%$ levels are indicated by $*, * *, * * *$, respectively.

\begin{tabular}{|c|c|c|c|c|}
\hline & \multicolumn{2}{|c|}{ Absolute Deal Size } & \multicolumn{2}{|c|}{ Relative Deal Size } \\
\hline & Clustered OLS & Fama-McBeth & Clustered OLS & Fama-McBeth \\
\hline \multirow[t]{2}{*}{$\mathrm{UA}_{1}$} & $0.009 * * *$ & 0.005 & -0.001 & -0.002 \\
\hline & (3.44) & $(1.55)$ & $(-0.38)$ & $(-0.94)$ \\
\hline \multirow{2}{*}{$\mathrm{UA}_{2}$} & $0.017 * * *$ & $0.013 * * *$ & $-0.005 * * *$ & -0.002 \\
\hline & $(5.78)$ & (3.87) & $(-4.18)$ & $(-0.97)$ \\
\hline \multirow[t]{2}{*}{$\mathrm{UA}_{3}$} & $0.021 * * *$ & $0.017 * * *$ & $0.017 * * *$ & $0.012 * * *$ \\
\hline & (7.14) & $(5.26)$ & $(5.80)$ & (3.22) \\
\hline \multirow[t]{2}{*}{$\mathrm{UA}_{4}$} & $0.017 * * *$ & $0.011 * *$ & $0.020 * * *$ & $0.014 * * *$ \\
\hline & (5.12) & $(2.67)$ & $(4.48)$ & (3.29) \\
\hline \multirow[t]{2}{*}{ Rel. Deal Size } & $0.503 * *$ & $0.444^{*}$ & $0.449 * *$ & $0.457^{*}$ \\
\hline & $(2.71)$ & (1.83) & $(2.20)$ & (1.90) \\
\hline \multirow[t]{2}{*}{ Log Market Cap. } & $-0.417 * * *$ & $-0.402 * * *$ & $-0.336 * * *$ & $-0.341 * * *$ \\
\hline & $(-8.62)$ & $(-12.12)$ & $(-10.46)$ & $(-8.36)$ \\
\hline \multirow[t]{2}{*}{ Country Divers. } & $0.334 * *$ & $0.223^{*}$ & $0.347 *$ & $0.209^{*}$ \\
\hline & $(2.00)$ & $(1.98)$ & $(1.97)$ & $(1.79)$ \\
\hline \multirow[t]{2}{*}{ Industry Divers. } & -0.066 & -0.185 & -0.068 & -0.186 \\
\hline & $(-1.02)$ & $(-1.57)$ & $(-0.99)$ & $(-1.58)$ \\
\hline \multirow[t]{2}{*}{ Prior Acquisitions } & $0.011 * * *$ & -0.025 & $0.010 * * *$ & -0.028 \\
\hline & (3.96) & $(-1.13)$ & $(3.47)$ & $(-1.13)$ \\
\hline Time Effects & YES & - & YES & - \\
\hline Industry Effects & YES & YES & YES & YES \\
\hline $\mathrm{N}$ & 25,750 & & 25,750 & \\
\hline $\mathrm{R}^{2}$ & 0.026 & & 0.025 & \\
\hline \multicolumn{5}{|l|}{ Wald Tests: } \\
\hline $\mathrm{UA}_{1}-\mathrm{UA}_{2}=0$ & $30.60 * * *$ & & 0.73 & \\
\hline $\mathrm{UA}_{2}-\mathrm{UA}_{3}=0$ & $17.90 * * *$ & & $38.99 * * *$ & \\
\hline $\mathrm{UA}_{3}-\mathrm{UA}_{4}=0$ & 1.94 & & 1.37 & \\
\hline $\mathrm{UA}_{1}-\mathrm{UA}_{2}-\mathrm{UA}_{3}-\mathrm{UA}_{4}=0$ & $55.65 * * *$ & & $12.38 * * *$ & \\
\hline
\end{tabular}


Figure 1: CEO's Decision Problem

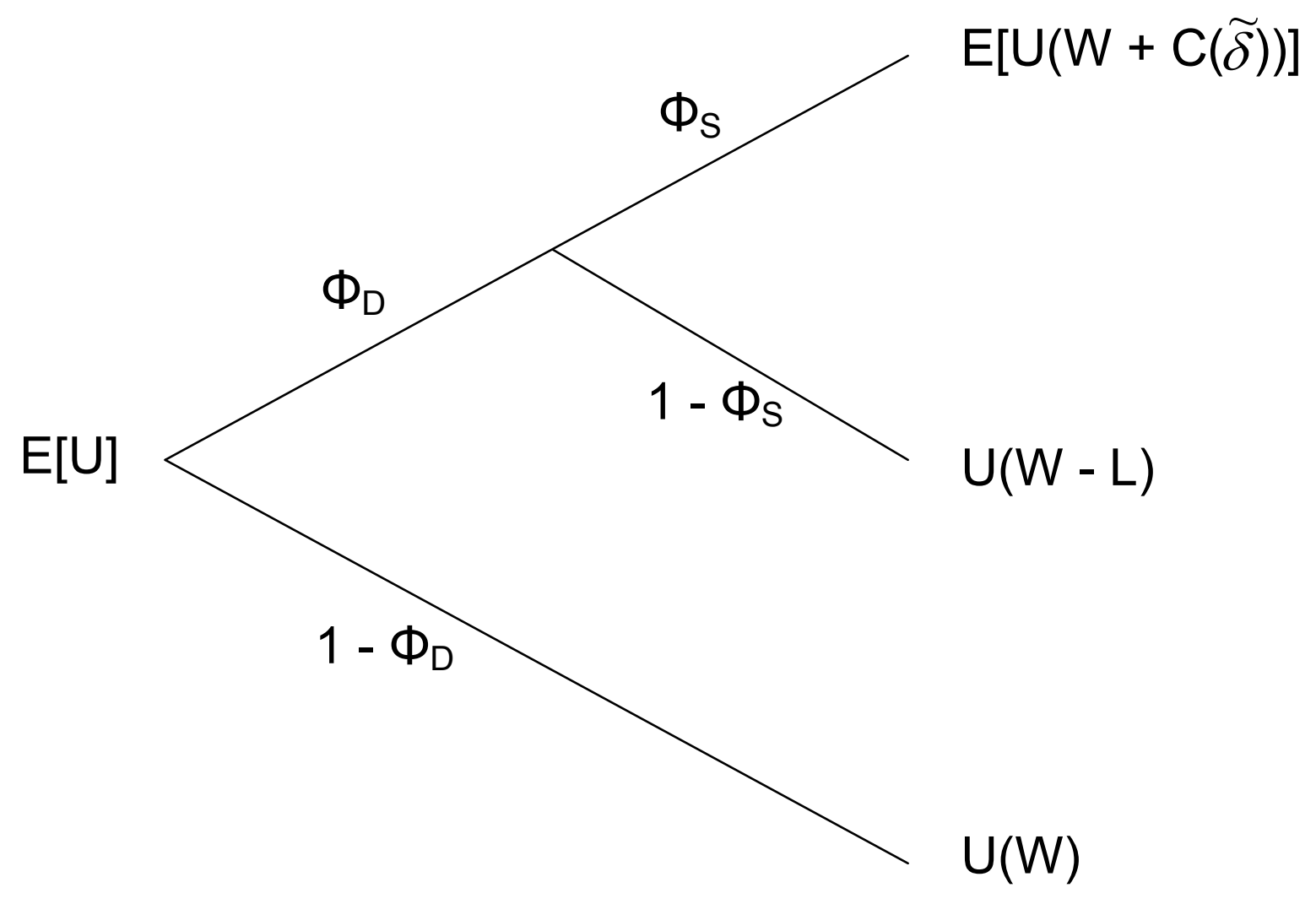

